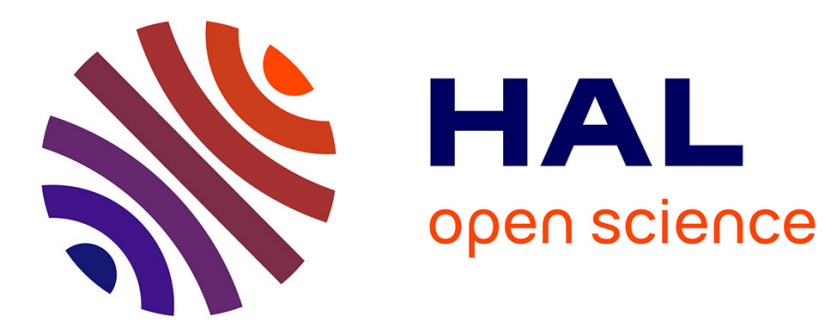

\title{
Photoscanning of CdTe detectors for investigation of crystal quality and contact behaviour
}

\author{
P.A. Tove, M. Slapa
}

\section{To cite this version:}

P.A. Tove, M. Slapa. Photoscanning of CdTe detectors for investigation of crystal quality and contact behaviour. Revue de Physique Appliquée, 1977, 12 (2), pp.349-353. 10.1051/rphysap:01977001202034900 . jpa-00244171

HAL Id: jpa-00244171

https://hal.science/jpa-00244171

Submitted on 1 Jan 1977

HAL is a multi-disciplinary open access archive for the deposit and dissemination of scientific research documents, whether they are published or not. The documents may come from teaching and research institutions in France or abroad, or from public or private research centers.
L'archive ouverte pluridisciplinaire HAL, est destinée au dépôt et à la diffusion de documents scientifiques de niveau recherche, publiés ou non, émanant des établissements d'enseignement et de recherche français ou étrangers, des laboratoires publics ou privés. 


\title{
PHOTOSCANNING OF CdTe DETECTORS FOR INVESTIGATION OF CRYSTAL QUALITY AND CONTACT BEHAVIOUR
}

\author{
P. A. TOVE and M. SLAPA $\left({ }^{*}\right)$ \\ Electronics Department, Institute of Technology, University of Uppsala, Uppsala, Sweden
}

\begin{abstract}
Résumé. - La surface de cristaux de tellurure de cadmium a été explorée par un faisceau laser émettant à $6328 \AA$ à la manière du balayage d'un tube TV. Le courant photogénéré a été mesuré en fonction d'un grand nombre de paramètres, citons, la nature des contacts, la présence d'un champ électrique, la polarité. On montre qu'il est possible de déduire de ces expériences des renseignements sur le type de conductivité, son homogénéité, la distribution du champ électrique et les propriétés de transport dans la zone désertée.
\end{abstract}

\begin{abstract}
N}$ and P-type semi-insulating cadmium telluride crystals have been scanned with a $6328 \AA$ laser beam performing a TV-type scan. The current response from the sample under test has been determined as a function of different parameters : nature of the contacts, electric field, polarity. It is demonstrated that information can be obtained on the type of conductivity of the material, its homogeneity, the field distribution and the transport properties of electrons and holes.
\end{abstract}

1. Introduction. - Photoscanning is a useful technique for investigating photosensitive semiconductor devices [1-4]. It involves mechanical or electronic scanning with a light beam over the device area. The response of the latter is recorded as a function of the position of the light spot.

Preliminary results are reported on light scanning of CdTe detectors with a mechanical scanning system using two mirrors fed by triangular waveforms using servosystems. The motions of the mirrors are at $90^{\circ}$ to each other ; one, the $\mathrm{X}$-scan is driven at a relatively high frequency, corresponding to typical scan times of $20 \mathrm{~ms}$, the other (Y-scan) at a lower pace to form a TV-type scan. The present light source was a red He-Ne laser (6 $328 \AA$ ), although the use of other light sources is anticipated.

Photoscanning is fast and convenient, e. g. compared with the much slower scanning using nuclear radiation.

The two modes of scanning generally used are the photo emf mode and the photoconductive mode, i. e. without and with detector bias. The response depends on the mode of carrier generation by the light and on the electrical transport properties of the crystal and its contacts. Here, we will show that information on the type of conductivity of the crystal and its variation over the wafer can be obtained, as well as on carrier behaviour and field distributions.

$\left(^{*}\right)$ On leave of absence from the Institute Nuclear Research Swierk, Warsaw, Poland.
2. Experimental arrangement. - In the present case a laser beam $(6328 \AA$, obtained from a $2 \mathrm{~mW}$ Hughes laser type $3222 \mathrm{H}-\mathrm{C}$, having a minimum of inherent amplitude light modulation) was reflected in turn by two mirrors mounted at $90^{\circ}$ angle to each other, before falling on the crystal surface. The light is absorbed in CdTe with an absorption length of approximately $10 \mu \mathrm{m}$. The two mirrors were driven in a sawtooth motion by servo-contoling amplifiers fed from two sawtooth generators. One mirror was driven at a fast pace, forming the $\mathrm{X}$-scan, and was synchronized to the lower speed Y-scan performed by the other mirror. The area scanned on the crystal could be adjusted by varying the two amplitudes of vibration, covering areas from several $\mathrm{cm}^{2}$ down to a few $\mathrm{mm}^{2}$. The diameter of the scanning light beam was of the order of $50 \mu \mathrm{m}$. General Scanning Inc. type CCX100 scanner controls with type G300PD and XY-300 scanner and mirror mount set-up were used. See figure 1. Two types of display were used, a) an X-Y-recorder when scanning was at a slow pace, b) an oscilloscope with a Polaroid camera for higher speed scanning. In both cases subsequent $\mathrm{X}$-scans (for different $\mathrm{Y}$ positions) could be separated in the display by adding a fraction of the Y-scan voltage to the signal response from the structure under test.

3. Results. - ChLORINE COMPENSATED MATERIAL. The result of scanning a Cl-doped CdTe-crystal (Strassbourg material) is seen in figure 2. This THM crystal sample had both faces polished and $5 \mathrm{~mm}$ 
FUNCTION GENERATORS
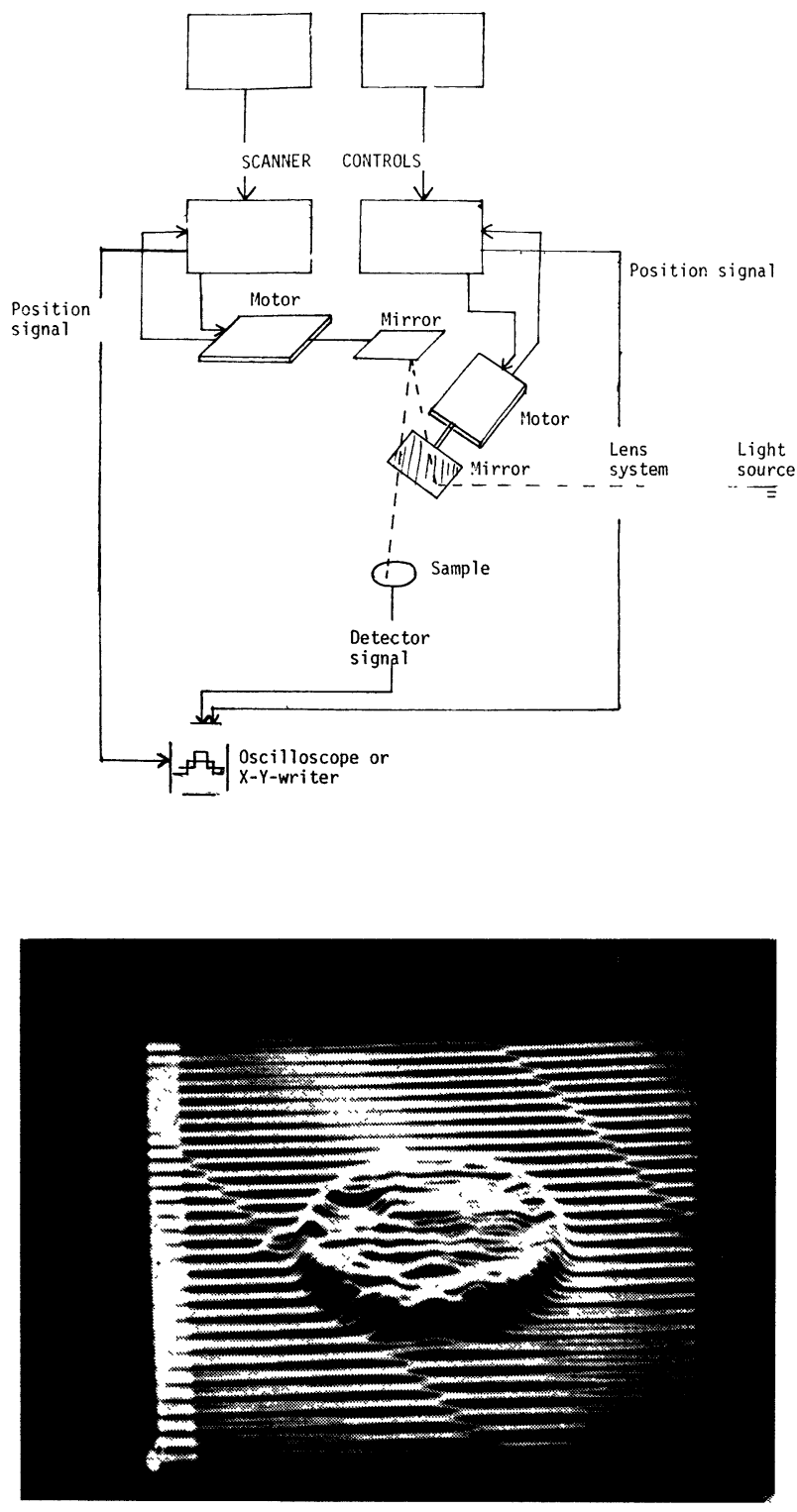

(a)

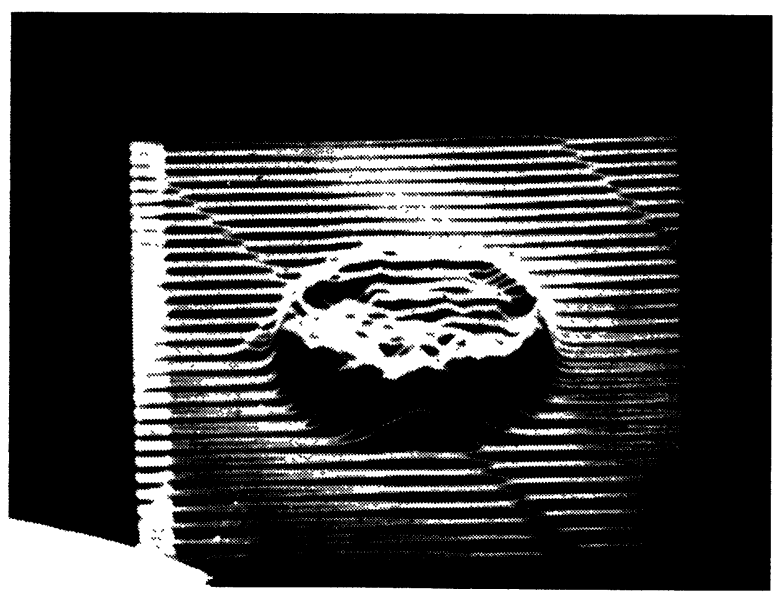

(b)

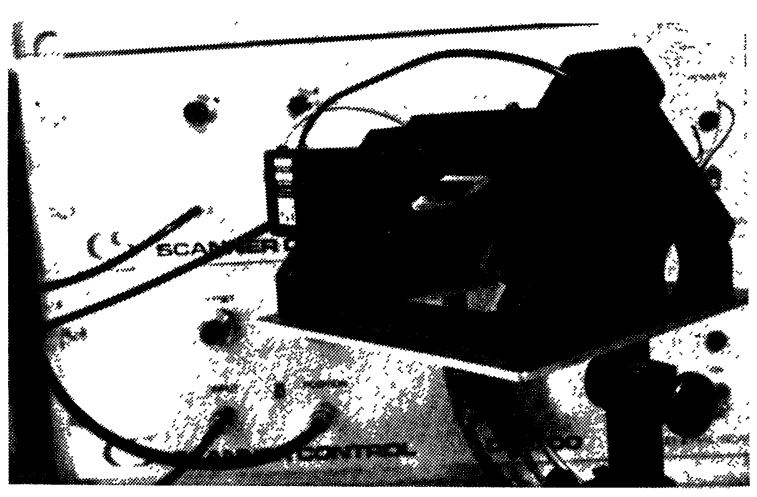

Fig. 1. - The set-up for photo-scanning.

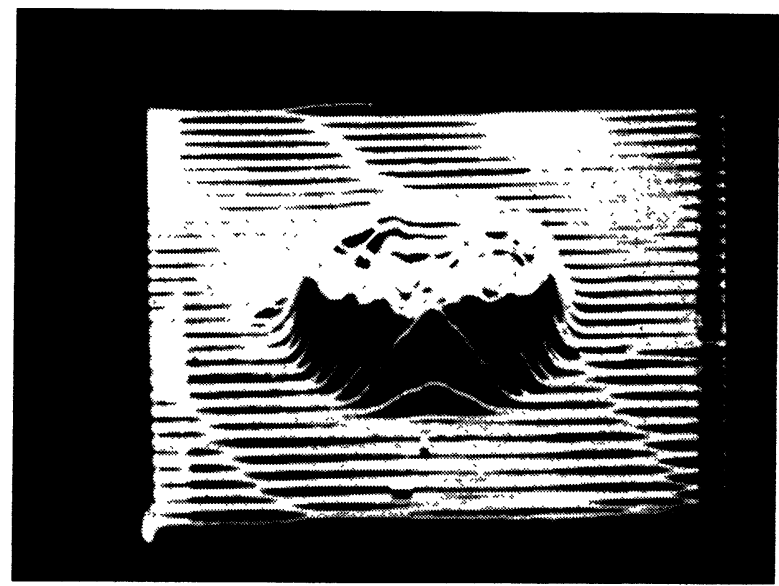

(c)

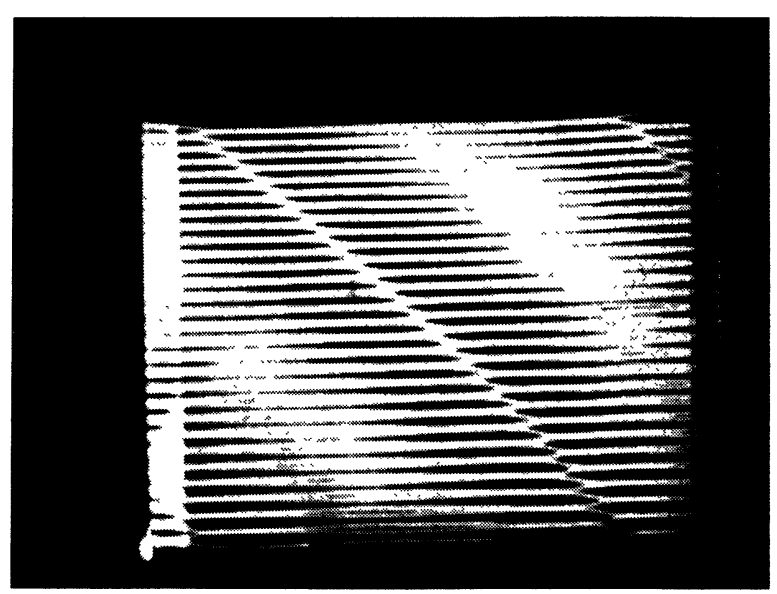

(d)

Fig. 2. - Results of scanning a Cl-doped crystal. 
diameter contacts were made by evaporating palladium. The bottom contact was $200 \AA$ thick while that exposed to the laser light was $90 \AA$ thick. It appears that for positive bias applied to the top contact a response, increasing with applied voltage, is observed $(100 \mathrm{~V}$, figure $2 a ; 300 \mathrm{~V}$, figure $2 b$ and $500 \mathrm{~V}$, figure $2 c$ ). When the irradiated top contact is biased negatively $(500 \mathrm{~V}$, figure $2 d$ ) no response is obtained. The observed behaviour is in agreement with what should be expected if the type of conductivity of the crystal is p-type, which is expected for chlorine doped material. For positive bias on the top contact we expect that a depletion region exists. This increases with voltage and extends from the surface. No response is observed outside the contact area. We attribute the relatively small response straggling inside the contact area to variations in resistivity and lifetime. For applied voltages of 100$500 \mathrm{~V}$ the depletion region becomes so thick that all carriers are generated there. Therefore, the increased response with bias is expected because the higher field strength causes the carriers (holes in this case) to generate a larger fraction of their maximum possible output signal there, as the Schubweg $\mu E \tau$ increases, according to the Hecht relation. Capacitance measurements were performed to get information of the extension of the depletion region. From the results, shown in figure 3 we deduce, using $C=\varepsilon \varepsilon_{0} A / \delta$ ( $A$ area, $\delta$ thickness of the depletion region), a depletion thickness of approximately $250 \mu \mathrm{m}$ at $100 \mathrm{~V}$ and $450 \mu \mathrm{m}$ at $500 \mathrm{~V}$. However, it is observed that the slope of the capacitance curve is not the expected square root of voltage. Shifting the position of the Fermi level and thus the net charge in the material (including that from traps) may change the apparent resistivity.
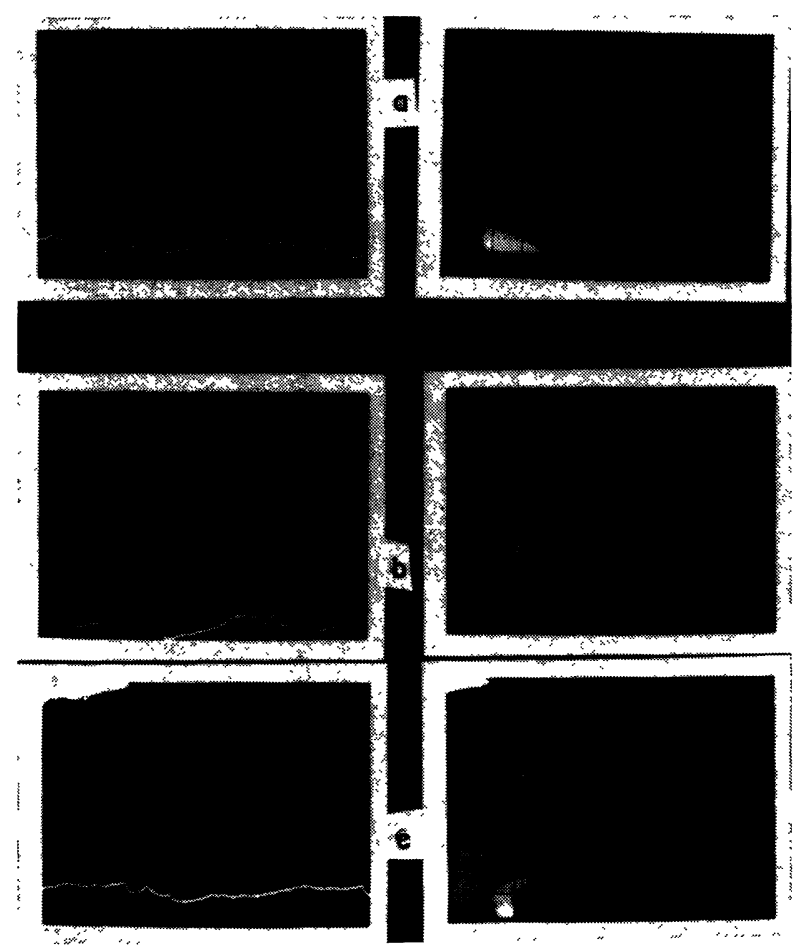

REVUE DE PHYSIQUE APPLIQUÉE. - T. 12, No 2, FÉVRIER 1977

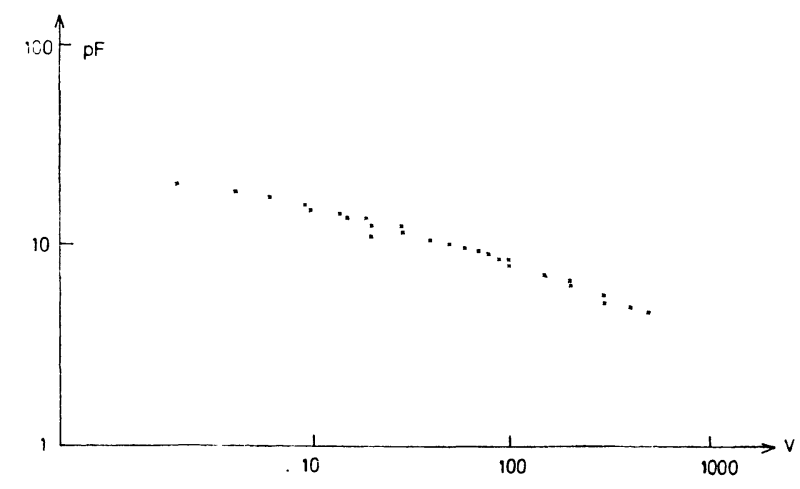

FIG. 3. - Results of capacitance measurements for the crystal of figure 2 (thickness $1.75 \mathrm{~mm}$, frequency $10 \mathrm{kHz}$ ).

- INDIUM COMPENSATED MATERIAL. - In figure 4-6 are shown results of scanning an Indium-doped crystal (Hughes Research Lab. material). A bottom contact of aquadag and a semitransparent palladium top electrode of about the same area were used. To the left in figure 4, which is for a negative bias of $35 \mathrm{~V}$, are shown transverse scans at different positions along the long dimension of the contact. For the middle scan it is obvious that the beam passes across an abnormal spot in the crystal because the response decreases sharply (the signal is phase-reversed by the amplifier ; for the applied bias polarity we expect a positive signal). The dimension of the region of singularity can be judged from the intensity-modulated displays of the photos to the right which resulted from $X-Y$ scans over that particular area (different intensity settings were used for the three pictures shown). In figure 5 are shown the result of scans without applied bias. The larger res-
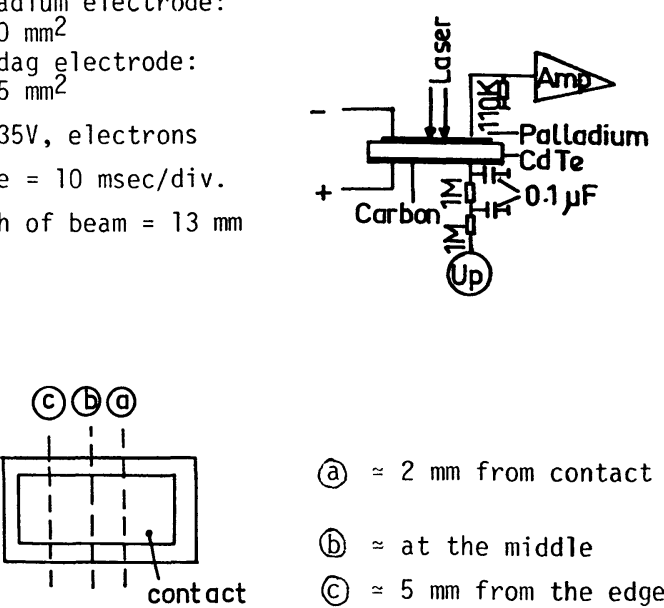

(a) $\simeq 2 \mathrm{~mm}$ from contact

(b) $\approx$ at the middle

(c) $\simeq 5 \mathrm{~mm}$ from the edge

FIG. 4. - Scanning with negative bias, $35 \mathrm{~V}$ on semitransparent Pd top contact of an In-doped crystal. 
(b)

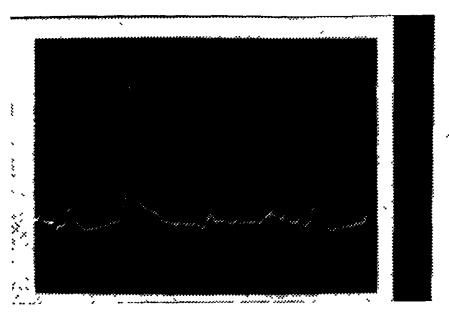

Detector: KZ-1 - CdTe

Wafer: $38 \times 15 \times 2.6 \mathrm{~mm}^{2}$

Palladium electrode: $30 \times 10 \mathrm{~mm}^{2}$

Aquadag electrode: $38 \times 15 \mathrm{~mm}^{2}$

$U_{\mathrm{p}}=0 \mathrm{~V}$

Scale $=10 \mathrm{~mm} / \mathrm{div}$

Width of beam $=13 \mathrm{~mm}$
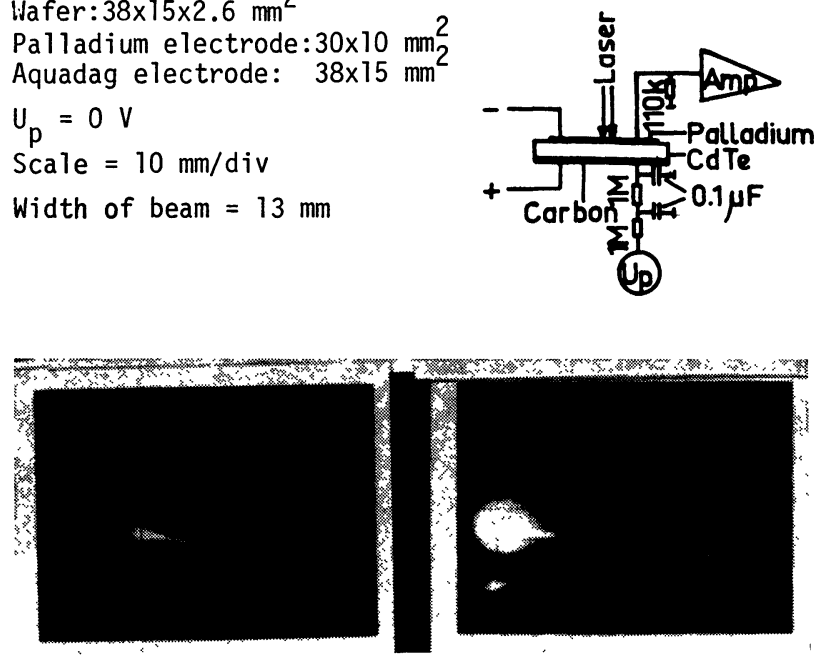

FIG. 5. - Scanning with no bias.

Erratum: With the value of scale, read, $10 \mathrm{~ms} / \mathrm{div}$ instead of $10 \mathrm{~mm} / \mathrm{div}$.

ponse in figure 4 compared with figure 5 is in agreement with the signal increase expected for a bias of such polarity as to give increased depletion region thickness on n-type material (n-type conductivity is expected for indium-doped material). The negligible response shown in figure 6, which is for positive bias on the top contact is expected if this corresponds to forward-biasing, resulting in a negligible depletion region where the moving carriers (holes) can generate no signal. On the other hand we observe some increased response at the contact edge which may indicate a region of radially directed field here.

We can get some information about the region of singularity found in figure 4 by looking in more detail on the scanning result for zero bias shown infigure 5 . As a start for the discussion we use the potential diagram of figure 7 . Here we have assumed that the palladium contact fixes the Fermi level at about midgap position (c. f. results of Siffert and Ponpon, this conference). The saturation photoemf voltage obtained for this barrier structure equals the diffusion voltage $V_{\mathrm{d}}$ and is approached when the illumination density is sufficiently high, as in this case with laser illumination. This corresponds to the condition where the band bending at the junction has been flattened out by the introduction of the photogenerated carriers, so that the (c)
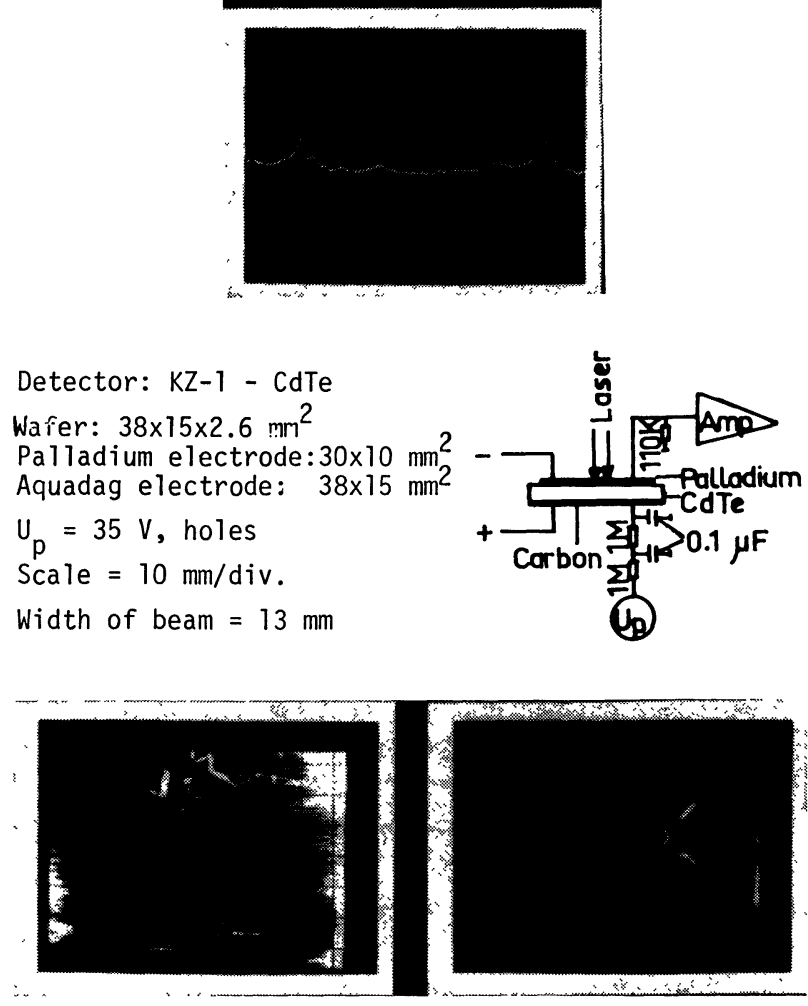

Fig. 6. - Scanning with positive bias, $35 \mathrm{~V}$ on top contact. Erratum: With the value of scale, read, $10 \mathrm{~ms} / \mathrm{div}$ instead of $10 \mathrm{~mm} /$ div.

Fermi level on the right side of figure 7 becomes higher with the amount $V_{\mathrm{d}}$ than that on the metal side, meaning that the metal contact becomes positive compared to the crystal. This is indeed the polarity observed for the main part of the crystal in figure 5 (taking amplifier reversal into account). From the sensitivity of the oscilloscope used in obtaining figure 5 we derive a value of $V_{\mathrm{d}} \simeq 0.2 \mathrm{eV}$. Using figure 7 we then deduce the position of the Fermi level to be $\simeq 0.55 \mathrm{eV}$ below the conduction band. From the relation between the location of the Fermi level and the carrier concentration in CdTe given in figure 12 of ref. [5], we conclude that this corresponds to a carrier concentration of $n \simeq 10^{10} \mathrm{~cm}^{-3}$ which assuming an electron mobility of $1000 \mathrm{~cm}^{2} / \mathrm{V} \mathrm{s}$, gives a resistivity of $\simeq 10^{6} \Omega \mathrm{cm}$. The point of singularity in the top left scan of figure 5 corresponds to a polarity of the output voltage of opposite sign to that of the

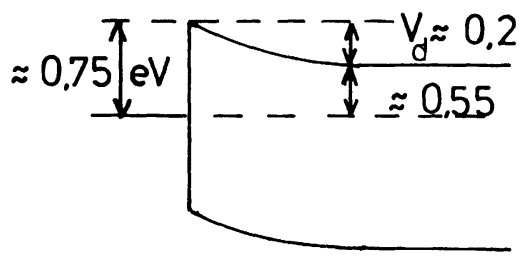

Fig. 7. - Band diagram for a Pd contact on CdTe. 
remaining part of the crystal, indicating that we here have a p-type crystallite. The output voltage here again is $\simeq 0.2 \mathrm{~V}$ corresponding to a carrier concentration of $p \simeq 10^{9} \mathrm{~cm}^{-3}$. For a hole mobility of $100 \mathrm{~cm}^{2} / \mathrm{V}$ s this corresponds to a resistivity of $10^{8} \Omega \mathrm{cm}$.

4. Discussion. - Photoscanning as a means of studying the properties of $\mathrm{CdTe}$ detector crystals is much faster and gives similar information as X-ray or $\alpha$-particle scanning about regions where the field strength, or/and carrier $\mu \tau$-product is too low for giving effective charge collection. Though the wavelength of light may be chosen to get absorption at a desired depth the method as used here was limited to surface regions. The method gives additional information about local variations in resistivity', lifetime or contact barrier effects. It may be difficult to distinguish between different origins; this applies also to the effects of $\mu \tau$ or $E$. Semiquantitative determination of the local variation of the resistivity (or the contact barrier height) may be obtained.

Further possibilities may be offered by pulsing the light at the source (or interrupting charge generation by placing opaque patterns on the crystal). Observing the signal may then give information on the local decay time of carrier concentration.

Acknowledgements. - The CdTe crystals were supplied by P. Siffert and K. Zanio. We also thank Göran Boberg for help with the measurements. In the early phase of the work a scanner at the UCLA School of Nuclear Medicine was used.

\section{References}

[1] Tihanyi, J., Pasztor, N. G., Solid-State Electron. 10 (1967) 235.

[2] Potter, C. N. and SAwyer, D. E., Rev. Sci. Instrum. 39 (1968) 180.
[3] SChyler, V., Rev. Sci. Instrum. 38 (1967) 1374.

[4] McMahron, R. E., Electronics 12/4 (1971) 92

[5] Siffert, P., Berger, J., Scharager, C., Cornet, A. Stuck, R., IEEE Trans. Nucl. Sci. NS-23 (1976) 159. 